\title{
PENGARUH EDUKASI VIDEO LATIHAN FISIK TERHADAP PENGETAHUAN PASIEN YANG MENJALANI HEMODIALISIS DI RS PKU MUHAMMADIYAH YOGYAKARTA
}

\section{EFFECTIVENESS OF PHYSICAL ACTIVITY EXERCISE VIDEO EDUCATION TO HEMODIALYSIS PATIENT KNOWLEDGE IN RS PKU MUHAMMADIYAH YOGYAKARTA}

\author{
Ambar Relawati ${ }^{1 *}$, Isnina Noor Sakinah ${ }^{2}$, Rahmawati Dian Nurani $^{3}$ \\ *1Universitas Muhammadiyah Yogyakarta, Jl. Brawijaya, Kasihan, Bantul, Yogyakarta 55183, \\ Email: aambarrelawati@yahoo.com, Indonesia \\ 2Universitas Muhammadiyah Yogyakarta, Jl. Brawijaya, Kasihan, Bantul, Yogyakarta 55183, Indonesia \\ ${ }^{3}$ Universitas Muhammadiyah Yogyakarta, Jl. Brawijaya, Kasihan, Bantul, Yogyakarta 55183, Indonesia
}

\begin{abstract}
Background: Chronic Kidney Disease (CKD) is a progressive and irreversible kidney damage or dysfunction caused by the body's failure to maintain metabolism, fluid and electrolyte balance. Most of the CKD in Indonesia is diagnosed an advanced and late stage, so dialysis is necessary to solve this problem. The most common complaints of hemodialysis patients are muscle weakness. Patients with muscle weakness are due to reduced activity, muscle atrophy, muscle myopathy, neuropathy or a combination of them. One way that can be done as muscle strengthening to support and protect the internal organs and tissues is to do physical exercise. Physical exercises include flexibility exercises, strengthening exercises, and cardiovascular exercises. The exercise was done by giving video education to the patient for 60-90 minutes and 2 sets at the time of hemodialysis. Video is one of the educational media so that patients easily understand and imitate the steps of physical exercise.

Objective: To know effectiveness of patient education with video to hemodialysis patient knowledge about physical activity exercise.

Methods: This study used quasi experimental method with one-group design pre-post test design.

Results: This research is a non parametric statistic test with Wilcoxon test method and got the result of $0.000(p<0,05)$.

Conclusions: Video education can improve the knowledge of patients with chronic renal failure who run hemodialysis.
\end{abstract}

Keywords: Chronic Kidney Disease (CKD), hemodialysis, Physical Exercise, Video Education.

\section{PENDAHULUAN}

Penyakit ginjal kronik (PGK) merupakan kerusakan atau disfungsi ginjal yang progresif dan irreversible ditandai dengan penurunan laju filtrasi glomerulus (LFG) kurang dari $60 \mathrm{~mL} /$ menit $/ 1,73 \mathrm{~m}^{2}$ selama lebih dari 3 bulan, dan terdapat peningkatan kadar kreatinin dalam darah. ${ }^{1}$ Hal ini diakibatkan karena tubuh gagal dalam mempertahankan metabolisme serta keseimbangan cairan dan elektrolit sehingga menyebabkan uremia. ${ }^{2}$ Penyakit ginjal kronis tidak dapat dikembalikan atau dipulihkan dan terjadi penurunan progresif jaringan fungsi ginjal. $^{3}$ Ketika massa ginjal yang tersisa tidak dapat lagi menjaga lingkungan internal tubuh, maka akibatnya adalah gagal ginjal.

Penyakit ginjal kronis adalah penyebab kesembilan kematian di Amerika Serikat (AS). ${ }^{4}$ Di Amerika Serikat, kejadian dan prevalensi gagal ginjal meningkat $50 \%$ di tahun 2014. ${ }^{5}$ Prevalensi PGK pada tahun 
2013 telah meningkat 50\% dari tahun sebelumnya. $^{6}$ Negara-negara maju seperti China diperkirakan lebih dari 100 juta penduduk yang mengalami PGK. ${ }^{7}$

Kejadian gagal ginjal kronis di Indonesia pada populasi umur $\geq 15$ tahun sebanyak 0,2 \%. Angka ini lebih rendah dibandingkan dengan prevalensi penyakit gagal ginjal kronik di negara lain. Penelitian Pernefri tahun 2006 yang mendapatkan prevalensi penderita gagal ginjal kronis sebesar 12,5 \%. Hal ini karena Riskesdas 2013 hanya menangkap data orang yang terdiagnosa gagal ginjal kronis sedangkan sebagian besar gagal ginjal kronis di Indonesia baru terdiagnosis pada tahap lanjut dan akhir.

Hemodialisis merupakan salah satu tindakan dialisis yang digunakan pada pasien dengan penyakit ginjal stadium terminal yang membutuhkan terapi jangka panjang atau permanen. $^{8}$ Hemodialisis menyebabkan peningkatan harapan hidup pada pasien, namun tidak berpengaruh pada penyakit ginjal yang mendasarinya. ${ }^{9}$ Selama hemodialisis, mesin sebagian menggantikan fungsi ginjal oleh sirkulasi darah pasien melalui ginjal buatan. ${ }^{10}$

Salah satu permasalahan yang sering dikeluhkan pasien yang menjalani hemodialisis rutin adalah kelemahan otot. Pasien mengalami kelemahan otot tersebut disebabkan adanya pengurangan aktivitas, atrofi otot, miopati otot, neuropati, atau kombinasi di antaranya. ${ }^{11}$ Salah satu cara yang dapat dilakukan sebagai penguatan otot untuk mendukung dan melindungi organorgan dalam dan jaringan adalah melakukan latihan fisik.

Latihan fisik merupakan pergerakan terencana dan terstruktur yang dilakukan untuk memperbaiki atau memelihara satu atau lebih aspek kebugaran fisik. ${ }^{12}$ Latihan fisik penting untuk mempertahankan dan meningkatkan kesehatan tubuh secara keseluruhan. Latihan fisik dilakukan meliputi latihan fleksibilitas untuk membantu persendian bekerja dengan halus dan membantu untuk menekuk sendi, menyentuh dan memindahkan benda lebih mudah. Latihan fleksibilitas menggunakan peregangan otot halus dan gerakan yang lambat. Latihan penguatan untuk membuat otot menjadi lebih kuat. Latihan penguatan menggunakan tahanan (beban, elastik beban, atau beban pasien sendiri) untuk membuat otot menjadi lebih keras dan kuat. Latihan atau exercise (disebut juga aerobik atau latihan ketahanan) ini untuk jantung, paru, dan sirkulasi bekerja lebih efesien. Latihan kardiovaskuler mengembangkan daya tahan sehingga dapat aktif lebih lama tanpa merasa lelah. ${ }^{13}$

Latihan fisik dapat diberikan melalui edukasi atau pendidikan kesehatan saat menjalani hemodialisis sehingga dapat dievaluasi. Pendidikan kesehatan dapat membantu seseorang mengambil sikap yang bijaksana terhadap kesehatan dan kualitas hidup. $^{14}$ Dengan adanya pendidikan 
kesehatan akan terjadi peningkatan pengetahuan dan pendidikan untuk membantu individu dan masyarakat dalam meningkatkan kesehatan dengan mempengaruhi sikap mereka. ${ }^{15}$ Salah satu faktor yang mempengaruhi pengetahuan dan keterampilan adalah informasi, semakin banyak informasi yang didapat pada seseorang, maka pengetahuan dan keterampilannya akan semakin meningkat juga. $^{16}$

Berdasarkan latar belakang di atas, perlunya dilakukan pemberian edukasi terkait latihan fisik yang dapat dilakukan oleh pasien dan keluarga dalam bentuk media video yang dapat dijangkau pasien dan keluarga. Salah satunya adalah edukasi tentang latihan fisik untuk pasien gagal ginjal yang menjalani hemodialisis. Memberikan implementasi metode edukasi video dapat meningkatkan kualitas hidup pasien hemodialisis. ${ }^{17}$ Tujuan dari penelitian ini adalah untuk meningkatkan pengetahuan pasien dan keluarga dengan memberikan edukasi melalui media video terkait latihan fisik pada pasien PGK yang terpasang av shunt agar terhindar dari kekakuan otot.

\section{BAHAN DAN CARA PENELITIAN}

Metode yang digunakan pada penelitian ini adalah menggunakan metode quasi eksperimen dengan rancangan onegroup pre-post test design. Penelitian ini dilaksanakan di Unit Hemodialisa RS PKU Muhammadiyah Yogyakarta. Dilakukan dua kali dalam 1 minggu. Sesi I hari Selasa, 16 Januari 2018, pukul 08.00 - 10.00 WIB. Sesi II hari Sabtu, 20 Januari 2018, pukul 08.00 10.00 WIB.

Populasi dalam penelitian ini adalah semua pasien yang rutin menjalani hemodialisis di RS PKU Muhammadiyah Yogyakarta sebanyak 148 orang. Sedangkan sampel dalam penelitian ini berjumlah 37 orang dengan cara purposive sampling.

Variabel yang digunakan pada penelitian ini adalah variabel pengetahuan dengan menggunakan alat ukur kuesioner. Instrumen yang digunakan yaitu video serta booklet berisi latihan fisik untuk menambah pengetahuan pada pasien hemodialisis.

Pengambilan data dilakukan di RS PKU Muhammadiyah pada pasien yang rutin menjalani hemodialisis. Tahap awal, peneliti mengidentifikasi data responden serta melakukan inform consent. Setelah itu dilakukan pre test terkait pengetahuan pasien terhadap latihan fisik pada pasien yang menjalani hemodialisis. Lalu diberikan edukasi dengan media video terkait latihan fisik, dilanjutkan dengan post test setelah edukasi selesai.

Uji stastistik menggunakan uji non parametric yaitu uji Wilcoxon untuk mengetahui perbedaan pengetahuan sebelum dan sesudah dilakukan intervensi. Analisa data menggunakan program komputer. 


\section{HASIL DAN PEMBAHASAN}

\section{Gambaran Karakteristik Responden}

Responden penelitian yaitu pasien yang rutin menjalani hemodialisis di RS PKU Muhammadiyah Yogyakarta berjumlah 37 orang. Adapun karakteristik responden dijelaskan tabel sebagai berikut :

Tabel 1. Karakteristik Responden $(n=37)$

\begin{tabular}{|c|c|c|}
\hline $\begin{array}{l}\text { Karakteristik } \\
\text { responden }\end{array}$ & $\begin{array}{l}\text { Jumlah } \\
\text { (f) }\end{array}$ & $\begin{array}{c}\text { Persentase } \\
(\%)\end{array}$ \\
\hline \multicolumn{3}{|l|}{ Jenis kelamin } \\
\hline Laki-laki & 21 & 56,8 \\
\hline Perempuan & 16 & 43,2 \\
\hline \multicolumn{3}{|l|}{ Tingkat } \\
\hline pendidikan & 7 & 18,9 \\
\hline SD & 4 & 10,8 \\
\hline SMP & 16 & 43,3 \\
\hline SMA & 4 & 10,8 \\
\hline Diploma & 5 & 13,5 \\
\hline Sarjana & 1 & 2,7 \\
\hline Doktor & & \\
\hline \multicolumn{3}{|l|}{ Pekerjaan } \\
\hline Pensiunan & 4 & 10,8 \\
\hline Wiraswasta & 4 & 10,8 \\
\hline Karyawan & 4 & 10,8 \\
\hline Buruh & 2 & 5,4 \\
\hline Dosen & 1 & 2,7 \\
\hline Petani & 1 & 2,7 \\
\hline Tidak Bekerja & 21 & 56,7 \\
\hline \multicolumn{3}{|l|}{ Usia (DepKes, } \\
\hline $\begin{array}{l}\text { 2009) } \\
26-35 \text { tahun }\end{array}$ & $\begin{array}{c}4 \\
10\end{array}$ & $\begin{array}{l}10,8 \\
27.0\end{array}$ \\
\hline 36-45 tahun & 10 & 27,0 \\
\hline 46-55 tahun & 7 & 18,9 \\
\hline $\begin{array}{l}56-65 \text { tahun } \\
65 \text {-atas }\end{array}$ & 6 & 16,2 \\
\hline
\end{tabular}

Sumber: Data Primer 2018

Tabel 1 menunjukkan karakteristik responden pasien PGK di RS PKU Muhammadiyah Yogyakarta. Jenis kelamin laki-laki lebih banyak yang melakukan hemodialisis dibanding perempuan yaitu 21 orang $(56,8 \%)$. Tingkat Pendidikan tertinggi yaitu pada jenjang SMA sebesar 16 orang Pengaruh Edukasi Video Latihan Fisik Terhadap Pengetahuan Pasien yang Menjalani Hemodialisis di RS PKU Muhammadiyah Yogyakarta

Ambar Relawati, Isnina Noor Sakinah, Rahmawati Dian Nurani MIK P-ISSN 2252-3413, E-ISSN 2548-6268
(43,3\%). Berdasarkan pekerjaan responden, paling banyak yang tidak bekerja yaitu 21 orang $(56,7 \%)$. Usia tertinggi yaitu pada usia antara 36-45 dan 46-55 sebesar 10 orang $(27,0 \%)$.

\section{Analisis Uji Statistik}

Sebelum dilakukan uji statistik, terlebih dahulu dilakukan uji normalitas data menggunakan Uji Shapiro-wilk $(<50)$ dengan hasil sebagai berikut :

\section{Tabel 2. Uji Normalitas data pada variabel pengetahuan Pre-test dan Post test Variabel P value \\ Pengetahuan Pre Test 0,000 \\ Sumber: Data Primer 2018}

Tabel 2 uji normalitas Shapiro-wilk didapatkan hasil 0,000 menunjukkan bahwa $p$ value $<$ 0,05 maka dapat dikatakan bahwa data tidak berdistribusi normal, sehingga dapat dianalisis dengan statistik nonparametrik yaitu uji Wilcoxon.

Berikut tabel uji Wilcoxon untuk mengetahui perbedaan nilai pengetahuan pre test dan post test dengan hasil sebagai berikut:

Tabel 3. Hasil perbedaan pengetahuan responden

\begin{tabular}{cccc}
\hline $\begin{array}{c}\text { Pengetahua } \\
\text { n }\end{array}$ & Mean \pm SD & Nilai z & p value \\
\hline Pre-test & $48,65 \pm 14,75$ & $-4,850$ & 0,000 \\
Post-test & $73,24 \pm 15,99$ & & \\
\hline \multicolumn{4}{c}{ Sumber: Data Primer 2018} \\
\end{tabular}

Tabel 3 menunjukkan mean nilai pengetahuan sebelum (pre-test) diberikan edukasi video sebesar 48,65 dan meningkat setelah (post test) diberikan edukasi video menjadi 73,24 . Perbedaan pengetahuan pre- 
test dan post test menunjukkan $p$ value 0,000 $(p<0,05)$ maka edukasi video terkait latihan fisik pada pasien hemodialisis dapat meningkatkan pengetahuan pasien PGK.

\section{Pembahasan}

Latihan fisik yang dilakukan selama tindakan hemodialisis dapat meningkatkan kekuatan otot diantaranya otot tangan dan otot kaki serta dapat meningkatkan ukuran otot dan memperbaiki fungsi otot. Latihan fisik pada pasien hemodialisis juga akan menurunkan kadar kreatinin pada pasien sesuai penelitian Latihan fisik yang dilakukan akan merangsang pertumbuhan pembuluh darah kapiler dalam otot sehingga tubuh akan terbantu dalam menghantarkan oksigen dan memperbaiki sirkulasi darah. Hal ini akan menurunkan tekanan darah serta mengeluarkan hasil sampah metabolik seperti asam laktat.

Waktu untuk melakukan latihan fisik agar dapat meningkatkan kekuatan otot yaitu selama 30 sampai 45 menit dan secara umum diberikan sebelum hemodialisis selesai dilakukan. Latihan dilakukan 2 set, 8 pengulangan untuk kelompok otot besar ekstremitas atas (tangan) dan bawah (kaki). ${ }^{11}$

Peningkatan kekuatan otot pada pasien yang melakukan latihan fisik juga dibuktikan dalam penelitian yang dilakukan oleh Barcellos (2015) dalam penelitiannya tentang Effect of Exercise in the Whole Spectrum of Chronic Kidney Disease : A Sistematic Review, dalam penelitian ini dikatakan bahwa efek peningkatan kekuatan otot akan bertambah secara signifikan setelah dilakukan latihan selama 6 bulan. ${ }^{18}$ Latihan fisik dapat dilihat hasil yang signifikan apabila latihan dilakukan antara 4-6 bulan secara teratur 3 kali seminggu dan lama latihan antara $30-90$ menit. $^{11}$

Latihan fisik meliputi peregangan leher, peregangan tangan/lengan, peregangan bahu, punggung, dan dada. Gerakan lain meliputi latihan penguatan yang meliputi penguatan lengan dengan memberikan beban pada tangan serta penguatan paha dengan memberikan beban pada kaki serta gerakan untuk pendinginan. Menurut Heiwei (2014) latihan fisik yang dilakukan dengan intensitas tinggi yang dipadukan dengan latihan kardiovaskuler. ${ }^{11}$

Latihan fisik ini diberikan melalui edukasi dengan media video serta diperagakan oleh peneliti dan diikuti secara langsung oleh responden. Salah satu konten yang perlu diberikan saat pemberian edukasi pada pasien yang dilakukan hemodialisis adalah tentang latihan fisik, selain tentang pembatasan cairan, manajemen nutrisi perawatan vaskular akses, ginjal dan fungsinya, hemodialisis dan selfmanagement. ${ }^{19}$

Pada penelitian ini, latihan fisik dilakukan sebanyak $2 x$ pengulangan selama 30 menit melalui edukasi video. Lama pemberian edukasi pada pasien hemodialisis antara 60-90 menit, dengan frekuensi pemberian edukasi minimal 1 kali per minggu 
hingga 1 kali per bulan dengan lama pemberian informasi 6 bulan. ${ }^{20}$

Pemberian edukasi dengan media video signifikan mempengaruhi pengetahuan pasien apabila dilakukan dengan memberikan informasi dengan tatap muka, sehingga akan ada interaksi antara edukator dengan pasien hemodialisis. ${ }^{17}$ Selain itu, peneliti menggunakan booklet sebagai instrument untuk mendukung jalannya penelitian. Booklet dapat dipelajari disaat santai dan ukurannya yang kecil mudah dibawa, memuat informasi yang detail yang tidak mungkin disampaikan secara lisan, serta mengurangi kegiatan mencatat. Konten edukasi yang diberikan disesuaikan dengan kebutuhan pasien dan mempertimbangkan keadaan saat pasien pulang kerumah. ${ }^{14}$

Berdasarkan hasil penelitian terkait edukasi dengan media video terkait latihan fisik yang telah dilakukan, pada kelompok pre-test (sebelum dilakukan edukasi) terdapat 22 orang $(59,5 \%)$ yang memiliki pengetahuan kurang baik dan 15 orang yang memiliki pengetahuan tentang latihan fisik sudah baik $(40,5 \%)$.

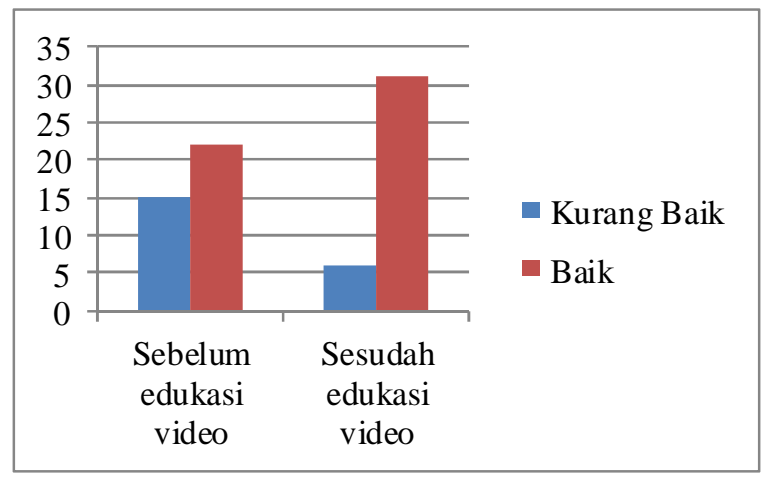

Saat dilakukan post-test (setelah edukasi) terdapat peningkatan pengetahuan pada pasien di ruang Hemodialisis RS PKU Muhammadiyah Yogyakarta yaitu pengetahuan yang sudah baik mencapai 31 orang $(83,8 \%)$ dan 6 orang $(16,2 \%)$ memiliki pengetahuan masih kurang baik.

$$
\text { Berdasarkan hasil uji Wilcoxon }
$$
didapatkan $p$ value $0,000(P<0,05)$, hal ini dapat disimpulkan bahwa pengetahuan pasien setelah dilakukan edukasi terkait video latihan fisik pada pasien hemodialisis berpengaruh dalam peningkatan pengetahuan pasien. Hal ini sejalan dengan penelitian Prihatin, menggunakan uji Wilcoxon test dengan $p$ value 0,000 menunjukkan bahwa terdapat perbedaan bermakna edukasi yang diberikan kepada pasien dan keluarga yang mengalami gagal ginjal kronik sebelum dan sesudah dilakukan edukasi kesehatan. Penelitian lain menunjukkan hasil $p$ value 0,004 menunjukkan bahwa terdapat perbedaan bermakna mengenai pengetahuan tentang PGK sebelum dan sesudah dilakukan edukasi kesehatan. ${ }^{2122}$

\section{KESIMPULAN}

Berdasarkan hasil uji Wilcoxon didapatkan $p$ value $0,000(p<0,05)$, dapat disimpulkan bahwa terdapat peningkatan pengetahuan pasien setelah dilakukan edukasi terkait video latihan fisik pada pasien hemodialisis. 
Setelah dilakukan edukasi video dan pemberian booklet, diharapkan pasien yang sedang menjalani hemodialisis dapat melakukan latihan fisik di rumah dengan dibantu oleh keluarga serta membaca melalui booklet yang telah diberikan agar dapat menjaga kekuatan otot pada bagian yang terpasang av shunt.

Diharapkan agar Institusi RS PKU Muhammadiyah Yogyakarta dapat bekerja sama dengan ruang hemodialisis untuk menerapkan video tersebut secara berkelanjutan pada pasien yang rutin menjalani hemodialisis.

Pemberian edukasi pada pasien di ruang Hemodialisis dapat dilakukan dengan memutarkan video pada saat pasien menjalani terapi hemodialisis sehingga pasien dapat mengikuti latihan fisik.

Diharapkan peneliti selanjutnya dapat memberikan inovasi-inovasi terbaru untuk meningkatkan pengetahuan terkait latihan fisik pada pasien PGK yang terpasang av shunt.

\section{TERIMA KASIH}

1. Dr. H. Mohammad Komarudin., Sp.A, Direktur Utama RS PKU Muhammadiyah Yogyakarta

2. Fitri Arofiati, S.Kep., Ns., MAN., Ph.D, Ketua Program Studi Magister Keperawatan Universitas Muhammadiyah Yogyakarta (UMY)

\section{KEPUSTAKAAN}

1. Kidney Disease Improving Global Outcome. KDIGO Clinical practice guideline for the evaluation and management of chronic kidney disease. Kidney Int Suppl. 2013;3(1):1-150.

2. Bararah, Taqiyyah dan Jauhar M. Asuhan Keperawatan, Panduan Lengkap Menjadi Perawat Profesional, Jilid 2. Jakarta : Prestasi Pustaka; 2013.

3. Black, Joyce $M$ dan Hawks, Jane Hokanson. Keperawatan Medikal Bedah. Manajemen Klinis untuk Hasil yang Diharapkan. Edisi Bahasa Indonesia. Edisi 8, Buku 1. Singapore; 2014.

4. Elsevier. Anggraini, F., \& Putri, A. F. Pemantauan Intake Output Cairan pada Pasien Gagal Ginjal Kronik dapat Mencegah Overload Cairan. Jurnal Keperawatan Indonesia; 2017. p. 152-160

5. Elmoghazy et.al. Nursing Intervention for Enhancing Hemodialysis Patient Adherence to Therapeutic Regimen. Journal of American Science: 2016; p. 12(11).

6. Zhang $L$, Wang $F$, Wang L, Wang W, Liu $\mathrm{B}$, Liu J, Chen M, He Q, Liao Y, Yu X, Chen N. Prevalence of chronic kidney disease in China: a cross-sectional survey. The Lancet. 2012.

7. Pusat Data Dan Informasi Kementerian Kesehatan RI. "Infodatin". Kementerian Kesehatan R.I (Online). 2017. [cited 21 Juni 2018] http://www.depkes.go.id/resources/downl oad/pusdatin/infodatin/infodatin\%20ginjal $\% 202017$.pdf

8. Smeltzer, S. C., \& Bare, B. G. Buku Ajar Keperawatan Medikal Bedah Brunner dan Suddarth. Edisi 8 Volume 2. Jakarta : EGC; 2013.

9. Poorgholami et.al. The Effect of Stress Management Training on Hope in Hemodialysis Patients. Global Journal of Health Science; 2016; Vol. 8, No. 7; 2016. ISSN 1916-9736 E-ISSN 1916-9744. Published by Canadian Center of Science and Education

10. Lovink et.al. Patients' experience of safety during haemodialysis treatment-a qualitative study. Journal of Advanced Nursing; 2015. 
11. Sulistyaningsih, D. R. Efektivitas Latihan Fisik Selama Hemodialisis Terhadap Peningkatan Kekuatan Otot Pasien Penyakit Ginjal Kronik di Rumah Sakit Umum 1).

12. Segura-Ortí, E.. Exercise in haemodialysis patients: a systematic review. Nefrologia; 2010. p. 30(2).

13. Erman, I. S. M., \& Sureskiarti, E. Analisa Praktik Keperawatan pada Pasien CKD (Chronic Kidney Diasea) dengan Intervensi Inovasi Aroma Terapi Rose Danguide Imagery terhadap Penurunan Tekanan Darah di Ruang Hemodialisa RSUD Abdul Wahab Sjahranie Samarinda Tahun 2017; 2017.

14. Suiraoka, I. P., \& Supariasa, I. D. Media Pendidikan Kesehatan. Yogyakarta : Graha IImu; 2012.

15. Kuniawati, D. P. Pengaruh Edukasi Terhadap Kepatuhan Intake Cairan Pasien Penyakit Ginjal Kronik (PGK) On Hemodialisis. Universitas Airlangga; 2015.

16. Potter \& Perry). Renata Kumalasari dkk, (Alih Bahasa) Fundamental Keperawatan : EGC Jakarta; 2006.

17. Maslakpak dan Shams. A Comparison of Face to Face and Video-Based Self Care Education on Quality of Life of Hemodialysis Patients. IJCBNM. 2015;3(3):234-243.

18. Barcellos, F. C., Santos, I. S., Umpierre, D., Bohlke, M., \& Hallal, P. C. Effects of exercise in the whole spectrum of chronic kidney disease: a systematic review. Clinical kidney journal. 2015; 8(6), 753-765.

19. Feizalahzadeh, Hossein et all. Development and Validation of a TheoryBased Multimedia Aplication for Educating Persian Patient Hemodialysis, Wolter Kluwer Health, Lippincot Williams \& Wilkins. 2014.

20. Lopez-Vargas, Pamela A, Craig, Jonathan C. Educational Intervention for Patient With CKD : Systematic Review, America Journal of Kidney Disease, Pages 353-370, DOI 10.1053/j.ajks.2016.01.022

21. Prihatin LD, Marini G, Kep S. Pengaruh Pendidikan Kesehatan dengan Video
Terhadap Pengetahuan dan Ketrampilan Keluarga Merawat Double Lumen Pasien Penyakit Ginjal Kronik (PGK) yang Menjalani Hemodalisis di Rsud Dr Soetomo Surabaya. Universitas Muhammadiyah Surabaya; 2016.

22. Widyastuti, R. Korelasi Lama Menjalani Hemodialisis dengan Indeks Massa Tubuh Pasien Gagal Ginjal Kronik di RSUD Arifin Achmad Provinsi Riau. Jurnal Gizi Volume 1 No.2. Poltekkes Kemenkes Riau: Riau; 2014 